Review

\title{
Bioavailability of Coffee Chlorogenic Acids and Green Tea Flavan-3-ols
}

\section{Daniele Del Rio ${ }^{1}$, Angelique Stalmach ${ }^{2}$, Luca Calani ${ }^{1}$ and Alan Crozier ${ }^{2, *}$}

1 Human Nutrition Unit, Department of Public Health, University of Parma, Via Volturno 39, 43100 Parma, Italy; E-Mails: daniele.delrio@unipr.it (D.D.R.); luca.calani@nemo.unipr.it (L.C.)

2 Plant Products and Human Nutrition Group, Division of Developmental Medicine, Faculty of Medicine, Graham Kerr Building, University of Glasgow, Glasgow G12 8QQ, UK;

E-Mail: astalmach@hotmail.com

* Author to whom correspondence should be addressed; E-Mail: a.crozier@bio.gla.ac.uk.

Received: 5 July 2010; in revised form: 27 July 2010 / Accepted: 28 July 2010 /

Published: 29 July 2010

\begin{abstract}
This paper reviews recent human studies on the bioavailability of chlorogenic acids in coffee and green tea flavan-3-ols in which the identification of metabolites, catabolites and parent compounds in plasma, urine and ileal fluid was based on mass spectrometric methodology. Both the chlorogenic acids and the flavan-3-ols are absorbed in the small intestine and appear in the circulatory system predominantly as glucuronide, sulfate and methylated metabolites. Even when absorption occurs in the small intestine, feeding studies with ileostomists reveal that substantial amounts of the parent compounds and some of their metabolites appear in ileal fluid indicating that in volunteers with a functioning colon these compounds will pass to the large intestine where they are subjected to the action of the colonic microflora. A diversity of colonic-derived catabolites are absorbed into the bloodstream and pass through the body prior to excretion in urine. There is growing evidence that these compounds, which were little investigated until recently, are produced in quantity in the colon and form a key part of the bioavailability equation of flavonoids and related compounds that occur in fruits, vegetables and beverages. Recent evidence indicates that some colon-derived phenolic acids have in vitro anti-inflammatory activity.
\end{abstract}

Keywords: coffee; green tea; chlorogenic acids; flavan-3-ols; human bioavailability 


\section{Introduction}

Dietary phenolic compounds, comprise a diversity of flavonoids as well as simple and complex phenolic structures [1]. They are of substantial interest because of their perceived beneficial effects on health and are, arguably, among the most investigated group of compounds in nutritional research.

Flavonoids and phenolic compounds undergo methylation, sulfation and glucuronidation after ingestion, with reactions that occur in the small and large intestine and in hepatic cells [1,2] Unmetabolised flavonoids appear to be absorbed only rarely with trace quantities of (-)-epicatechin-3-O-gallate and (-)-epigallocatechin-3-O-gallate being reported to appear in the circulatory system, but not urine, following consumption of green tea by humans [3]. Analysis of ileal fluid collected from ileostomists after the ingestion of various foodstuffs indicate that even when dietary flavonoids are absorbed in the small intestine, substantial quantities none-the-less pass from the small to the large intestine [4,5]. In the colon they are subjected to the action of the microflora resulting in cleavage of conjugating sugars and ring fission of the released aglycones followed by other metabolic steps giving rise to a series of phenolic acid catabolites that can be absorbed into the portal vein and excreted in urine in amounts corresponding to $>20 \%$ of flavonoid intake [6,7]. Obtaining further information of the catabolism of polyphenols in the colon is emerging as a key target for research on the identity and origins of biologically active compounds derived from the diet. Microbial catabolites produced in this manner [8,9] may influence the local microflora, exerting prebiotic activity resulting in the selection of probiotic strains. In addition, the parent flavonoid molecules and the catabolites may be present in the colon in concentrations that have the potential to inhibit the proliferation of cancerous cells.

The aim of this article is to review more recent research on the bioavailability of dietary chlorogenic acids and flavan-3-ols, discussing the fate of these compounds as they pass through the body, being metabolised and absorbed in both the small and large intestine prior to urinary excretion. This will be done by reference to studies with coffee, which contains high concentrations of chlorogenic acids, and green tea which is a very rich source of flavan-3-ols. The review concentrates on human studies and where catabolites and related compounds were identified by mass spectrometric-based methods without recourse to the use of enzyme hydrolysis prior to analysis.

\section{Coffee}

Coffee, in different preparations, is widely consumed throughout the world, and contains high levels of phenolic compounds. A single serving provides between 20 and $675 \mathrm{mg}$ of chlorogenic acids depending on the type of roast and the volume consumed and regular consumers an easily have an intake in excess of $1 \mathrm{~g}$ per day [10,11]. Chlorogenic acids are a group of compounds comprising hydroxycinnamates, such as caffeic acid, ferulic acid, and p-coumaric acid, linked to quinic acid to form a range of conjugated structures known as caffeoylquinic acids (CQA), feruloylquinic acids (FQA), and p-coumaroylquinic acids all of which exist in several isomeric forms [10]. As well as

these compounds coffee also contains dicaffeoylquinic acids and caffeoylquinic acid lactones (CQAL) (Figure 1). 
Figure 1. Structures of chlorogenic acids occurring in coffee.

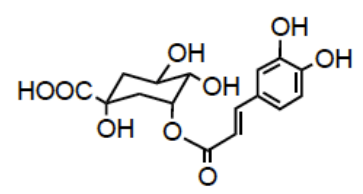

3-O-Caffeoylquinic acid

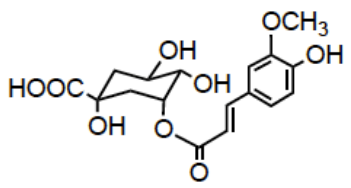

3-O-Feruloylquinic acid

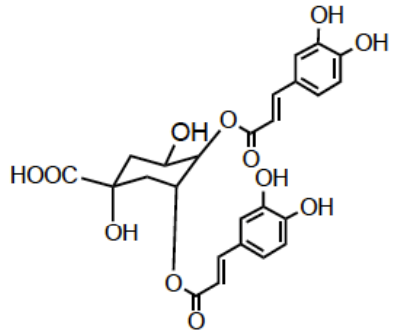

3,4-O-Dicaffeoylquinic acid

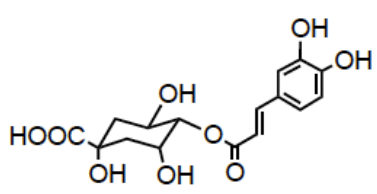

4-O-Caffeoylquinic acid

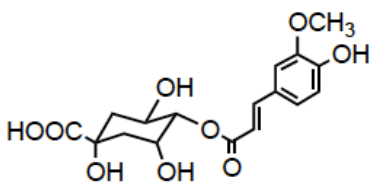

4-O-Feruloylquinic acid

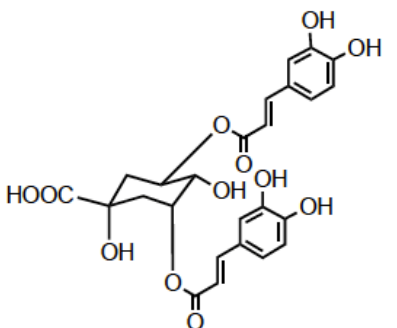

3,5-O-Dicaffeoylquinic acid

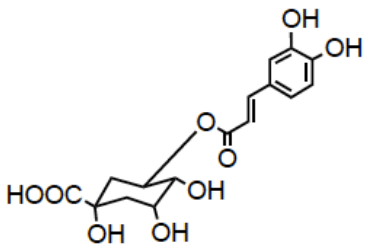

5-O-Caffeoylquinic acid

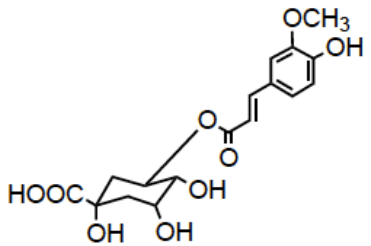

5-O-Feruloylquinic acid

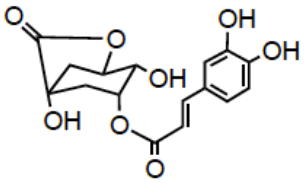

3-O-Caffeoylquinic acid lactone

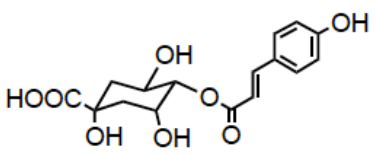

4-0-p-Coumaroylquinic acid<smiles>O=C(Cc1ccc(O)cc1)OOC1COC2COC(=O)C(O)C1O2</smiles>

4-O-Caffeoylquinic acid lactone

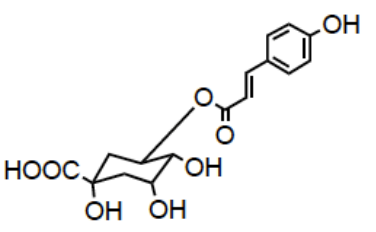

5-O-p-Coumaroylquinic acid

The literature describing the catabolism of coffee chlorogenic acids in human subjects is scarce and, in some instances, contradictory. A study by Nardini et al. [12] observed an increase of conjugated caffeic acid in plasma after the ingestion of $200 \mathrm{~mL}$ of coffee, while Rechner et al. [8] detected ferulic acid, isoferulic acid, dihydroferulic acid, 3-methoxy-4-hydroxybenzoic acid, hippuric acid and 3-hydroxyhippuric acid in urine from five human subjects after three ingestions of two cups of coffee at 4-h intervals. Monteiro et al. [13] reported the presence of unmetabolised CQAs in human plasma at a mean peak plasma concentration $\left(C_{\max }\right)$ of $7.7 \mu \mathrm{mol} / \mathrm{L} 2.3 \mathrm{~h}\left(T_{\max }\right)$ after acute ingestion of coffee containing 3,395 $\mu \mathrm{mol}$ of CQAs. Despite the high $C_{\max }$ of the CQAs, chlorogenic acids were not detected in urine collected $0-24 \mathrm{~h}$ after coffee intake. However, in a subsequent study by the same 
group, in which human volunteers consumed a coffee containing a much lower $451 \mu$ mol of chlorogenic acids, 4- and 5-O-CQAs were detected in sulfatase/glucuronidase-treated urine from some, but not all, subjects [14].

The most recent and detailed research on the fate of chlorogenic acids after the ingestion of coffee is that of Stalmach et al. [15,16] who in studies with healthy humans and ileostomists, in which analysis comprised HPLC-MS ${ }^{2}$-based methodology, noted that during passage through the body extensive metabolism of chlorogenic acids occurs with some compounds being absorbed in the small intestine and others in the colon. The plasma pharmacokinetic profiles of circulating chlorogenic acids and their metabolites observed with healthy subjects with a functioning colon, after the ingestion of $412 \mu \mathrm{mol}$ of chlorogenic acids are illustrated in Figure 2. Maximum $C_{\max }$ values ranged from $6 \mathrm{nmol} / \mathrm{L}$ for 5-FQA to $385 \mathrm{nmol} / \mathrm{L}$ for dihydroferulic acid, with the duration for $T_{\max }$ extending from $0.6 \mathrm{~h}$ (ferulic acid-4-O-sulfate, 3-CQLA-O-sulfate) to $5.2 \mathrm{~h}$ (dihydroferulic acid). The compounds detected in highest concentrations in plasma were free and sulfated conjugates of dihydroferulic acid and dihydrocaffeic acid acid with $C_{\max }$ values ranging from 41 to $385 \mathrm{nmol} / \mathrm{L}$. The $T_{\max }$ for these compounds was in a narrow range from 4.7 to $5.2 \mathrm{~h}$, indicating absorption in the large intestine. Much shorter $T_{\max }$ values of 0.6 to $1.0 \mathrm{~h}$, indicative of small intestine absorption, were obtained with 5-O-CQA, two CQLA-O-sulfates and three FQAs, all of which had relatively low $C_{\max }$ values (Figure 2). As noted by Stalmach et al. [15] most of the chlorogenic-derived compounds were rapidly removed from the circulatory system with elimination half-life $\left(T_{1 / 2}\right)$ values of 0.3 to $1.9 \mathrm{~h}$. The only compounds with an extended $T_{1 / 2}$ were dihydroferulic acid-4-O-sulfate $(4.7 \mathrm{~h})$, dihydroferulic acid-3-O-sulfate $(3.1 \mathrm{~h})$ and ferulic acid-4-O-sulfate which had an unusual biphasic plasma profile with dual $T_{\max }$ values at $0.6 \mathrm{~h}$ and $4.3 \mathrm{~h}$. The only unmetabolised compounds detected in plasma were three FQAs (Figure 2) and trace concentrations of 5-O-CQA $\left(C_{\max }-2.2 \mathrm{nmol} / \mathrm{L} ; T_{\max }-1.0 \mathrm{~h}\right)$. It is also of note that the free acid, dihydroferulic acid, as opposed to the more typical glucuronide and sulfate metabolites, was the principal component to accumulate in plasma which also contained dihydrocaffeic acid in a lower concentration (Figure 2).

The ileostomists drank a coffee with a very similar $385 \mu \mathrm{mol}$ chlorogenic acid profile to that ingested by the health subjects [16]. Plasma was not investigated but analysis of the $0-24 \mathrm{~h}$ ileal fluid revealed the presence of $275 \mu \mathrm{mol}$ of chlorogenic acids mainly, but not exclusively, as unmetabolised compounds. This indicates that $c a$. $30 \%$ of the chlorogenic acids were absorbed in the small intestine of the ileostomists and that in subjects with a functioning colon $c a$. $70 \%$ of intake will pass from the small to the large intestine.

The quantities of chlorogenic acids and their metabolites excreted in urine by healthy subjects and ileostomists over a $24 \mathrm{~h}$ period post-ingestion of coffee are summarised in Table 1 . The healthy volunteers excreted a total of $120.2 \mu \mathrm{mol}$ which corresponds to $29.2 \%$ of intake while urine from ileostomists contained $30.8 \mu \mathrm{mol}$ which equates with only $8.0 \%$ of the ingested chlorogenic acids. This highlights the importance of the colon in the bioavailability of dietary chlorogenic acids. 
Figure 2. Plasma pharmacokinetic profiles of circulating chlorogenic acids and metabolites, following the ingestion of $200 \mathrm{~mL}$ of coffee by health human subjects.
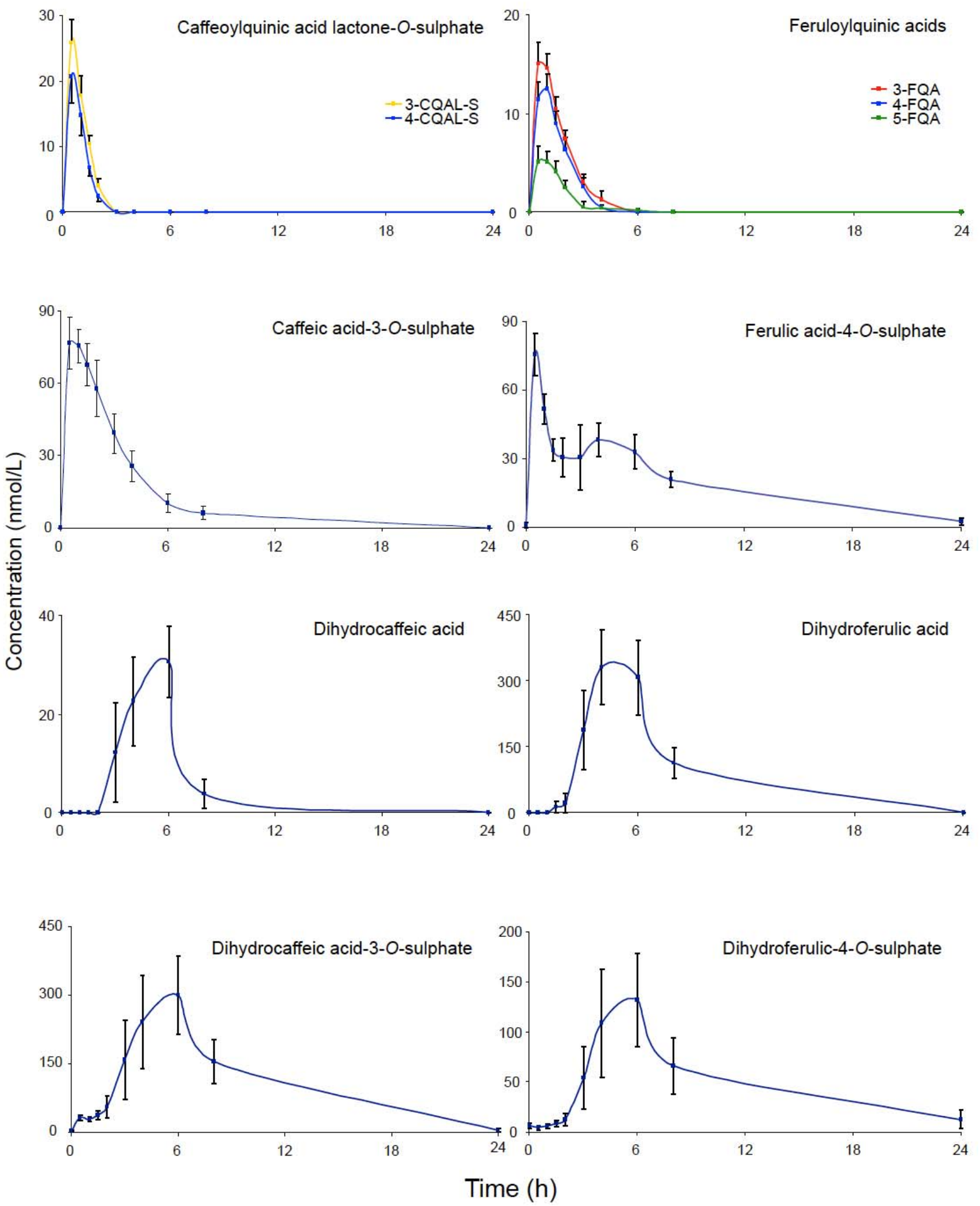
Table 1. Urinary excretion of chlorogenic acid metabolites in $0-24 \mathrm{~h}$ urine of healthy subjects $(n=11)$ and ileostomists $(n=5)$ following the ingestion of $200 \mathrm{~mL}$ of coffee.

\begin{tabular}{|c|c|c|}
\hline Chlorogenic acid and metabolites & $\begin{array}{l}\text { Subjects without a colon } \\
\text { (385 } \mu \text { mol ingested) }\end{array}$ & $\begin{array}{l}\text { Subjects with a colon } \\
\text { (412 } \mu \text { mol ingested) }\end{array}$ \\
\hline 3-O-Caffeoylquinic acid lactone- $O$-sulfate & $0.6 \pm 0.1$ & $1.1 \pm 0.1$ \\
\hline 4-O-Caffeoylquinic acid lactone- $O$-sulfate & $0.4 \pm 0.1$ & $1.0 \pm 0.1$ \\
\hline 3-O-Feruloylquinic acid & $0.9 \pm 0.2$ & $1.2 \pm 0.1$ \\
\hline 4-O-Feruloylquinic acid & $0.9 \pm 0.2$ & $1.1 \pm 0.1$ \\
\hline 5-O-Feruloylquinic acid & $1.1 \pm 0.2$ & $1.0 \pm 0.2$ \\
\hline Ferulic acid-4-O-sulfate & $9.9 \pm 1.9$ & $11.1 \pm 1.6$ \\
\hline Feruloylglycine & $2.1 \pm 0.3^{\mathrm{a}}$ & $20.7 \pm 3.9^{\mathrm{b}}$ \\
\hline Dihydroferulic acid & n.d. ${ }^{a}$ & $9.7 \pm 2.0^{\mathrm{b}}$ \\
\hline Dihydroferulic acid-4-O-sulfate & $0.8 \pm 0.2$ & $12.4 \pm 3.4$ \\
\hline Dihydroferulic acid-4-O-glucuronide & n.d. & $8.4 \pm 1.9$ \\
\hline Isoferulic acid-3-O-sulfate & $0.2 \pm 0.0$ & $0.4 \pm 0.1$ \\
\hline Isoferulic acid-3-O-glucuronide & $3.9 \pm 0.8$ & $4.8 \pm 0.5$ \\
\hline Dihydro-isoferulic acid-3-O-glucuronide & n.d. ${ }^{a}$ & $2.5 \pm 0.4^{\mathrm{b}}$ \\
\hline Caffeic acid-3-O-sulfate & $6.2 \pm 1.2$ & $6.4 \pm 0.8$ \\
\hline Caffeic acid-4-O-sulfate & $0.6 \pm 0.1$ & $0.6 \pm 0.1$ \\
\hline Dihydrocaffeic acid-3-O-sulfate & $3.2 \pm 0.9^{\mathrm{a}}$ & $37.1 \pm 8.2^{\mathrm{b}}$ \\
\hline Dihydrocaffeic acid-3-O-glucuronide & $n . d^{\mathrm{a}}$ & $0.7 \pm 0.2^{\mathrm{b}}$ \\
\hline Total & $30.8 \pm 4.3(8.0 \%)^{\mathrm{a}}$ & $120.2 \pm 17.0(29.2 \%)$ \\
\hline
\end{tabular}

\footnotetext{
${ }^{a}$ Data represent mean values in $\mathrm{mmol} \pm$ SE. n.d. not detected. Different superscripts within rows indicate a statistical difference between the two sets of volunteers (Two-sample T-test, P-value $<0.05$ ). Figures in bold italicised parentheses indicate excretion as a percentage of chlorogenic acid intake.
}

The data presented in Table 1 show that absence of a colon had minimal impact of the excretion of CQAL-O-sulfates and FQAs, as well as caffeic, ferulic and isoferulic acid-O-sulfates. Furthermore, the data indicate that the small intestine is most probably the site for i) cleavage of quinic acid from CQAs and FQAs releasing caffeic acid and ferulic acid, (ii) metabolism of caffeic acid to its 3- and 4-O-sulfates, and ferulic acid to ferulic acid-4-O-sulfate and iii) the methylation of caffeic acid to form isoferulic acid and its subsequent 3-O-sulfation and glucuronidation. In contrast, there were major reductions in the excretion of dihydrocaffeic acid-3-O-sulfate, dihydrocaffeic acid-3-O-glucuronide, dihydroferulic acid and its glucuronide and sulfated derivatives, dihydro-isoferulic acid-3-O-glucuronide and feruloylglycine by the ileostomists. This demonstrates that the colon is the site for i) the conversion of ferulic acid to feruloylglycine and dihydroferulic acid and ii) metabolism of caffeic acid to dihydrocaffeic acid which is further metabolised to dihydro-isoferulic acid. Despite its dual plasma $T_{\max }$ at 0.6 and $4.3 \mathrm{~h}$ in healthy subjects (Figure 2), urinary excretion of ferulic acid-4-O-sulfate was unaffected by the absence of a colon (Table 1) indicating that its secondary plasma $T_{\max }$ is not a consequence of colonic absorption. Stalmach et al. $[15,16]$ proposed the data obtained in their coffee feeding studies with healthy volunteers and ileostomists are in keeping with the metabolic routes illustrated in Figure 3. 
Figure 3. Proposed metabolism of chlorogenic acids following the ingestion of coffee by human volunteers. 5-O-CQA and 5-O-FQA are illustrated structures but their respective 3- and 4-isomers would be metabolized in a similar manner and likewise with 4-O-CQAL and 3-O-CQAL. COMT, catechol-O-methyltransferase; ET, esterase; RA, reductase; GT, UDP-glucuronyltransferase; ST, sulfuryltransferase; Co-A, co-enzyme A. Bold arrows indicate major routes, dotted arrows minor pathways. Steps blocked in subjects with an ileostomy and hence occurring in the colon are indicated.

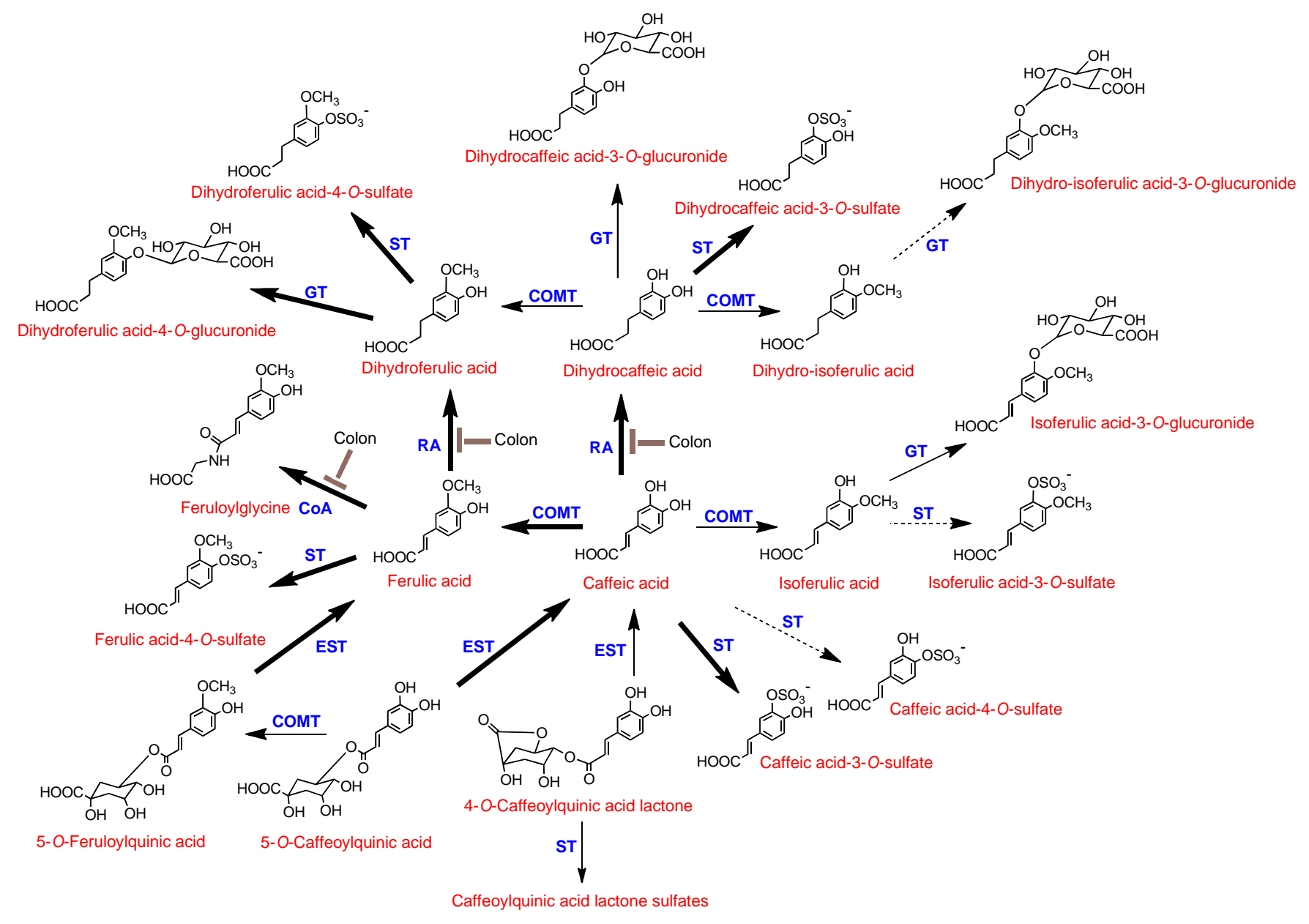

\section{Green Tea}

Green tea produced by aqueous infusion of young leaves of Camellia sinensis is a rich source of several flavan-3-ols (Figure 4), typically, with (-)-epigallocatechin-3-O-gallate, (-)-epigallocatechin and (-)-epicatechin predominating [17]. Recently, detailed information on the bioavailability of these compounds has appeared in the literature. In one study, ten healthy human subjects consumed $500 \mathrm{~mL}$ of green tea containing $648 \mu \mathrm{mol}$ of flavon-3-ols after which plasma and urine were collected over a $24 \mathrm{~h}$ period and analysed by HPLC-MS ${ }^{2}$ [3]. Plasma contained a total of twelve metabolites, in the form of $O$-methylated, sulfated and glucuronide conjugates of (epi)catechin and (epi)gallocatechin along with the native green tea flavan-3-ols (-)-epigallocatechin-3-O-gallate and (-)-epicatechin-3-O-gallate. Analysis of the pharmacokinetic profiles of these compounds, is presented in Table 2. 
Figure 4. Structures of green tea flavan-3-ols.<smiles>Oc1cc(O)c2c(c1)O[C@H](c1ccc(O)c(O)c1)C[C@H]2O</smiles>

(-)-Epicatechin<smiles>Oc1cc(O)c2c(c1)C[C@@H](O)[C@H](c1ccc(O)c(O)c1)O2</smiles>

(+)-Catechin<smiles>Oc1cc(O)c2c(c1)O[C@H](c1cc(O)c(O)c(O)c1)C2</smiles>

(+)-Gallocatechin<smiles>Oc1cc2c(O)c(O)c1C[C@H](O)O2</smiles>

(-)-Epigallocatechin<smiles>O=C(O[C@H]1Cc2cc(O)cc(O)c2O1)c1ccc(O)c(O)c1</smiles>

(-)-Epicatechin gallate<smiles>O=C(O[C@H]1Cc2cc(O)cc(O)c2O1)c1ccc(O)c(O)c1</smiles>

$(+)$-Catechin gallate<smiles></smiles>

(-)-Epigallocatechin gallate<smiles>O=C(O[C@H]1Cc2c(O)cc(O)cc2O1)c1cc(O)c(O)c(O)c1</smiles>

(+)-Gallocatechin gallate

Table 2. Pharmacokinetic analysis of flavan-3-ols and their metabolites detected in plasma of healthy volunteers following the ingestion of $500 \mathrm{~mL}$ of green tea. Data expressed as mean values $\pm \operatorname{SE}(n=10)$.

\begin{tabular}{lcc}
\hline Flavan-3-ols (number of isomers) & $C_{\max }(\mathrm{nmol} / \mathrm{L})$ & $T_{\max }(\mathrm{h})$ \\
\hline (Epi)gallocatechin-O-glucuronide (1) & $126 \pm 19$ & $2.2 \pm 0.2$ \\
4'-O-Methyl-(epi)gallocatechin-O-glucuronide (1) & $46 \pm 6.3$ & $2.3 \pm 0.3$ \\
4'-O-Methyl-(epi)gallocatechin-O-sulfates (2) & $79 \pm 12$ & $2.2 \pm 0.2$ \\
(Epi)catechin-O-glucuronide (1) & $29 \pm 4.7$ & $1.7 \pm 0.2$ \\
(Epi)catechin-O-sulfates (2) & $89 \pm 15$ & $1.6 \pm 0.2$ \\
O-Methyl-(epi)catechin-O-sulfates (5) & $90 \pm 15$ & $1.7 \pm 0.2$ \\
(-)-Epigallocatechin-3-O-gallate (1) & $55 \pm 12$ & $1.9 \pm 0.1$ \\
(-)-Epicatechin-3-O-gallate (1) & $25 \pm 3.0$ & $1.6 \pm 0.2$ \\
\hline
\end{tabular}

None of the flavan-3-ols were present in the circulatory system at $0 \mathrm{~h}$ but they were present in detectable quantities 30 min after green tea consumption. The main component to accumulate was an (epi)gallocatechin-O-glucuronide with $C_{\max }$ of $126 \mathrm{nmol} / \mathrm{L}$ and a $T_{\max }$ of $2.2 \mathrm{~h}$ while an (epi)catechin- $O$-glucuronide, probably the 3'-O-conjugate, attained a $C_{\max }$ of $29 \mathrm{nmol} / \mathrm{L}$ with a $1.7 \mathrm{~h} \quad T_{\max }$. The unmetabolised flavan-3-ols (-)-epigallocatechin-3-O-gallate and (-)-epicatechin-3-O-galllate has $C_{\max }$ values of 55 and $25 \mathrm{nmol} / \mathrm{L}$ after 1.6 and $2.3 \mathrm{~h}$ respectively. The $T_{\max }$ durations ranged from 1.6 to $2.3 \mathrm{~h}$ (Table 2) and all the flavan-3-ols and their metabolites were present in only trace quantities after $8 \mathrm{~h}$ and were not detected in the $24 \mathrm{~h}$ plasma. This is indicative of absorption in the small intestine, a fact confirmed when a similar flavan-3-ol metabolite plasma profile was obtained after the ingestion of green tea by humans subjects with an ileostomy [5].

Urine collected $0-24 \mathrm{~h}$ after green tea consumption by healthy subjects with a functioning colon contained a similar spectrum metabolites of (epi)catechin and (epi)gallocatechin to plasma except for the appearance of two (epi)catechin- $O$-sulfates and an absence of unmetabolised flavan-3-ols (Table 3). The overall metabolite excretion was equivalent to $8.1 \%$ of the $648 \mu$ mol flavan-3-ol intake. 
However, there was notable distinction between the excretion of (epi)catechin and (epi)gallocatechin metabolites. The recovery of (epi)gallocatechin metabolites was $11.4 \%$ while that of (epi)catechin metabolites was $28.5 \%$ of the (-)-epicatechin and (+)-catechin intake (Table 3). These high levels of excretion are also in keeping with recoveries obtained in earlier studies with green tea, cocoa and related products [18-20] confirming that (-)-epicatechin and (+)-catechin, in particular, are highly bioavailable being absorbed and excreted to a much greater extent than other flavonoids with the possible exception of isoflavones [1,2,21].

Table 3. Quantification of the major groups of flavan-3-ol metabolites excreted in urine 0-24 h after the ingestion of $500 \mathrm{~mL}$ of Choladi green tea by ten human volunteers. Data expressed as mean values in $\mu$ mol \pm standard error $(n=10)$. Italicised figures in parentheses indicate amount excreted as a percentage of intake.

\begin{tabular}{lc}
\hline Flavan-3-ol metabolites (number of isomers) & 0-24 h excretion ( $\mu$ mole) \\
\hline (Epi)gallocatechin-O-glucuronide (1) & 6.5 \\
4'-O-Methyl-(epi)gallocatechin-O-glucuronide (1) & 4.4 \\
4'-O-Methyl-(epi)gallocatechin-O-sulfates (2) & 19.8 \\
(Epi)gallocatechin-O-sulfates (3) & 2.6 \\
$\quad$ Total (epi)gallocatechin metabolites & $\mathbf{3 3 . 3 ~ ( 1 1 . 4 \% )}$ \\
(Epi)catechin-O-glucuronide (1) & $1.5 \pm 0.3$ \\
(Epi)catechin-O-sulphates (2) & $6.7 \pm 0.7$ \\
O-Methyl-(epi)catechin-O-sulphates (5) & $10.9 \pm 1.2$ \\
$\quad$ Total (epi)catechin metabolites & $\mathbf{1 9 . 1}(\mathbf{2 8 . 5 \% )}$ \\
\hline Total flavan-3-ol metabolites & $\mathbf{5 2 . 4 ~ ( 8 . 1 \% )}$ \\
\hline
\end{tabular}

Despite the relatively high absorption of flavan-3-ols in the small intestine, Stalmach et al. [5] report that after ileostomists drank green tea containing $634 \mu \mathrm{mol}$ of flavan-3-ols, $69 \%$ of the intake as mixture of native compounds and metabolites was excreted in 0-24 h ileal fluid. Thus, in volunteers with a functioning colon most of the ingested flavan-3-ols will almost certainly pass from the small to the large intestine where their fate is a key part of the overall bioavailability equation. To mimic these events two sets of experiments were carried out. Firstly, $50 \mu \mathrm{mol}$ of (-)-epicatechin, (-)-epigallocatechin and (-)-epigallocatechin-3-O-gallate were incubated under anaerobic conditions in vitro with fecal slurries and their degradation to phenolic acid by the bacterial microflora monitored. The main limitation of in vitro fermentation is that it may not fully depict the in vivo conditions. The removal of fecal material may alter the bacterial composition and thus may not represent the microflora in the colonic lumen and on the colonic mucosa where catabolism occurs in vivo. The accumulation and retention of the degradation products in the fermentation vessel makes collection, identification and quantification of the metabolites easier but is not necessarily representative of the events that occur in vivo where the actual concentration of a metabolite at any time interval is dependent on the combined rates of catabolism and absorption and this cannot be simulated in vitro. However, use of an in vitro model provides information on the types of breakdown products formed, helps elucidate the pathways involved, and the rate of catabolism can be determined. To complement the in vitro incubations, phenolic acids excreted in urine $0-24 \mathrm{~h}$ after i) the ingestion of green tea and 
water, in a cross over study, by healthy subjects, and ii) the consumption of green tea by ileostomist, was also investigated [22]. The data obtained in these studies provided the basis for the operation of the catabolic pathways that are illustrated in Figure 5.

Some of these catabolites, such as 4-hydroxyphenylacetic acid and hippuric acid were detected in urine from subjects with an ileostomy indicating that they are produced in the body by additional routes unrelated to colonic degradation of flavan-3-ols. It is, for instance, well known that there are pathways to hippuric acid from compounds such as benzoic acid, quinic acids [23], tryptophan, tyrosine and phenylalanine [24-26]. None-the-less, the elevated urinary excretion of hippuric acid and 4-hydroxyphenylacetic acid, occurring after green tea consumption, is likely to be partially derived from flavan-3-ol degradation. Earlier research showing statistically significant increases in urinary excretion of hippuric acid after consumption of both green and black tea by human subjects [23,27] supports this supposition.

Quantitative estimates of the extent of ring fission of the flavan-3-ol skeleton are difficult to assess because, as discussed above, the production of some of the phenolic acids was not exclusive to colonic degradation of flavan-3-ols. If these compounds, along with pyrogallol and pyrocatechol, which are derived from cleavage of the gallate moiety from (-)-epigallocatechin-3-O-gallate rather than ring fission, are excluded, excretion of the remaining urinary phenolic acids, namely 4-hydroxybenzoic acid, 3-methoxy-4-hydroxyphenylacetic acid, 3-(3'-hydroxyphenyl)-3-hydroxypropionic acid and 5-(3',4',5'-trihydroxyphenyl)- $\gamma$-valerolactone, was $210 \mu \mathrm{mol}$ after ingestion green tea compared to 38 $\mu \mathrm{mol}$ after drinking water. The $172 \mu \mathrm{mol}$ difference between these figures corresponds to a $39 \%$ degradation of the $439 \mu \mathrm{mol}$ of flavan-3-ols entering the colon after consumption of green tea. Added to this is the ca. 8\% excretion of glucuronide, sulfate and methylated flavan-3-ols originating from absorption in the small intestine. This combined estimate of a $47 \%$ recovery is nonetheless a minimum value because with the analytical methodology used some urinary catabolites will have escaped detection [22]. This will include glucuronide and sulfate metabolites of (-)-5-(3',4',5'-trihydroxyphenyl)- $\gamma$-valerolactone, (-)-5-(3',4' dihydroxyphenyl)- $\gamma$-valerolactone and (-)-5-(3',5' dihydroxyphenyl)- $\gamma$-valerolactone, which have been detected after green tea consumption with a cumulative $0-24 \mathrm{~h}$ excretion corresponding to $16 \%$ of flavan-3-ol intake [28-30]. More recently, in a similar study in which urine was collected for $24 \mathrm{~h}$ after green tea intake, valerolactone metabolites were excreted in quantities equivalent to $36 \%$ of intake [31]. When added to the $47 \%$ recovery estimated above, this gives a total excretion of $83 \%$ of intake. This figure is obviously an approximation because of factors such as different volunteers, flavan-3-ol intakes and analytical methodology. However, it does demonstrate that despite substantial modification as they pass through the body, there is a very high urinary recovery of flavan-3-ols, principally in the form of colon-derived catabolites. 
Figure 5. Proposed pathways involved in the colonic catabolism and urinary excretion of green tea flavan-3-ols. Following consumption of green tea more than $50 \%$ of the ingested (-)-epicatechin, (-)-epigallocatechin and (-)-epigallocatechin-3-O-gallate (blue structures) pass into the large intestine. When incubated with fecal slurries these compounds are catabolized by the colonic microflora probably via the pathways illustrated with red structures. Analysis of urine after green tea consumption indicates that some of the colonic catabolites enter the circulatory and undergo further metabolism before being excreted in urine. Green structures indicate catabolites detected in urine but not produced by fecal fermentation of (-)-epicatechin, (-)-epigallocatechin or (-)-epigallocatechin-3-O-gallate. The dotted arrow between pyrogallol and pyrocatechol indicate this is a minor conversion. Double arrows indicate conversions where the intermediate(s) did not accumulate and are unknown, although metabolism of 4-hydroxyphenylacetic acid to 3-methoxy-4-hydroxyphenylacetic acid probably proceeds via 3,4-dihydroxyphenylacetic acid. (IF) compounds detected in ileal fluid after green tea consumption; (F) catabolites detected in fecal slurries; (U) catabolites detected in urine; and $\left(^{*}\right)$ potential intermediates that did not accumulate in detectable quantities in either fecal slurries or urine.

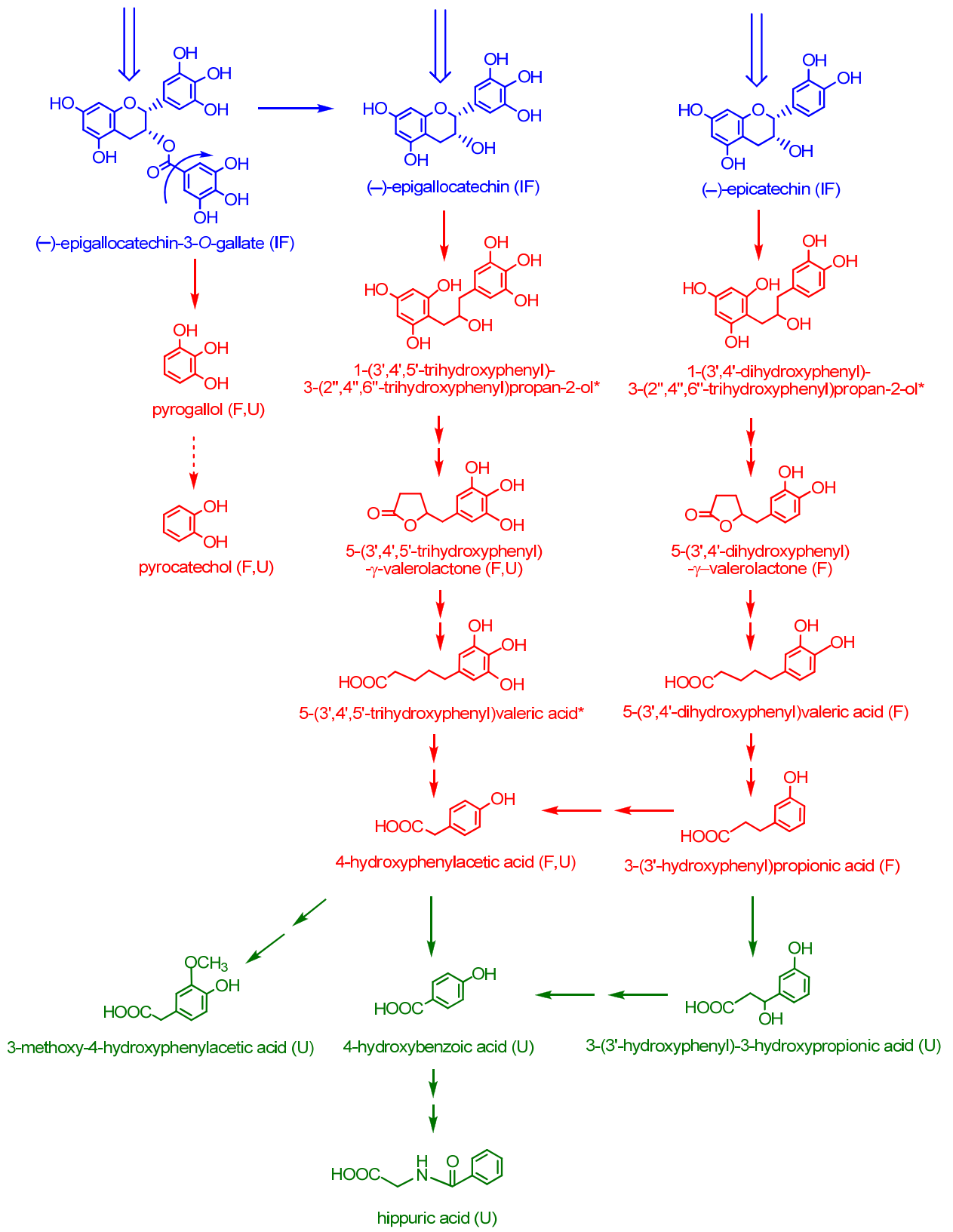




\section{Conclusions}

The recent publications that are reviewed in this paper established that both flavan-3-ols in green tea and chlorogenic acids in coffee undergo extensive metabolism prior to absorption, initially in the small intestine prior to passage to the large intestine where the colonic microflora-mediated production of phenolic acids occurs. The chlorogenic acids and the flavan-3-ols produce their own unique spectrum of colonic catabolites which are excreted in urine in substantial amounts corresponding to $29 \%$ of intake after coffee consumption and $\mathrm{ca}$. $83 \%$ after drinking green tea. Some, but far from all of the metabolites and colonic breakdown products appear transitorily in plasma, but seemingly are treated by the body as xenobiotics and are rapidly removed from the bloodstream. As a consequence, while analysis of plasma provides valuable information on the identity, $C_{\max }$ and $T_{\max }$ values of circulating metabolites after acute supplementation, estimates of 'area under the curve' values do not provide accurate quantitative assessments of uptake from the gastrointestinal tract. Urinary excretion provides a more realistic figure but, as this does not include the possibility of metabolites being sequestered in body tissues, this too is an under estimate of absorption, but to what degree remains to be determined.

There is a growing realisation that the colon plays an important role in the bioavailability of dietary phenolic and polyphenolic compounds with the studies discussed in this review showing that even when absorption occurs in the small intestine, substantial quantities pass to the large intestine where the parent compounds and their catabolites can impact on both colonic health and the colonic microflora. The level of urinary excretion indicates that substantial quantities of the colonic catabolites are absorbed into the portal vein and pass through the body in the circulatory system prior to excretion. Some of these compounds may play a key role in the protective effects of a fruit and vegetable-rich diet as there is evidence that they have anti-inflammatory activity in experimental models [32].

\section{References}

1. Crozier, A.; Jaganath, I.B.; Clifford, M.N. Dietary phenolics: chemistry, bioavailability and effects on health. Nat. Prod. Rep. 2009, 26, 1001-1043.

2. Donovan, J.L.; Manach, C.; Faulks, R.M.; Kroon P.A. Absorption and metabolism of dietary secondary metabolites. In Plant Secondary Metabolites. Occurrence, Structure and Role in the Human Diet. Crozier A., Clifford M.N., Ashihara H., Eds.; Blackwell Publishing: Oxford, UK, 2006; pp. 303-351.

3. Stalmach, A.; Troufflard, S.; Serafini, M.; Crozier, A. Absorption, metabolism and excretion of Choladi green tea flavan-3-ols by humans. Mol. Nutr. Food Res. 2009, 53, S44-53.

4. Olthof, M.R.; Hollman, P.C.; Katan, M.B. Chlorogenic acid and caffeic acid are absorbed in humans. J. Nutr. 2001, 131, 66-71.

5. Stalmach, A.; Mullen, W.; Steiling, H.; Williamson, G.; Lean, M.E.J.; Crozier, A. Absorption, metabolism, and excretion of green tea flavan-3-ols in humans with an ileostomy. Mol. Nutr. Food Res. 2010, 54, 323-334. 
6. Jaganath, I.B.; Mullen, W.; Edwards, C.A.; Crozier, A. The relative contribution of the small and large intestine to the absorption and metabolism of rutin in man. Free Rad. Res. 2006, 40, 1035-1046.

7. Roowi, S.; Mullen, W.; Edwards, C.A.; Crozier, A. Yoghurt impacts on the excretion of phenolic acids derived from colonic breakdown of orange juice flavanones in humans. Mol. Nutr. Food Res. 2009, 53, S68-S75

8. Rechner, A.R.; Spencer, J.P.E.; Kuhnle, G.; Hahn, U.; Rice-Evans, C.A. Novel biomarkers of the metabolism of caffeic acid derivatives in vivo. Free Rad. Biol. Med. 2001, 30, 1213-1222.

9. Aura, A.M. Microbial metabolism of dietary phenolic compounds in the colon. Phytochem. Rev. 2008, 7, 407-429.

10. Clifford, M.N. Chlorogenic acids and other cinnamates—nature, occurrence and dietary burden. $J$. Sci. Food Agric. 1999, 79, 362-372.

11. Stalmach, A.; Mullen, W.; Nagai, C.; Crozier, A. On-line HPLC analysis of the antioxidant activity of phenolic compounds in brewed paper-filtered coffee. Brasil. J. Plant Physiol. 2006, 18, 253-262.

12. Nardini, M.E.; Cirillo, F.; Natella, C.; Scaccini, C. Absorption of phenolic acids in humans after coffee consumption. J. Agric. Food Chem. 2002, 50, 5735-5741.

13. Monteiro, M.; Farah, A.; Perrone, D.; Trugo, L.C.; Donangelo, C. Chlorogenic acid compounds from coffee are differentially absorbed and metabolized in humans. J. Nutr. 2007, 137, 2196-2201.

14. Farah, A.; Monteiro, M.; Donangelo, C.M.; Lafay, S. Chlorogenic acids from green coffee extract are highly bioavailable in humans. J. Nutr. 2008, 138, 2309-2315.

15. Stalmach, A.; Mullen, W.; Barron, D.; Uchida, K.; Yokota, T.; Cavin, C.; Steiling, H.; Williamson, G.; Crozier, A. Metabolite profiling of hydroxycinnamate derivatives in plasma and urine after the ingestion of coffee by humans: identification of biomarkers of coffee consumption. Drug Metab. Dispos. 2009, 37, 1749-1758.

16. Stalmach, A.; Steiling, H.; Williamson, G.; Crozier, A. Bioavailability of chlorogenic acids following acute ingestion of coffee by humans with an ileostomy. Arch. Biochem. Biophys. 2010, [Epub ahead of print].

17. Del Rio, D.; Stewart, A.J.; Mullen, W.; Burns, J.; Lean, M.E.J.; Brighenti, F.; Crozier, A. HPLC-MS $^{\mathrm{n}}$ analysis of phenolic compounds and purine alkaloids in green and black tea. J. Agric. Food Chem. 2004, 52, 2807-2815.

18. Baba, S.; Osakabe, N.; Yasuda, A.; Natsume, M.; Takizawa, T.; Takizawa, T.; Nakamura, T.; Terao, J. Bioavailability of (-)-epicatechin upon intake of chocolate and cocoa in human volunteers. Free Rad. Res. 2000, 33, 635-641.

19. Auger, C.; Hara, Y.; Crozier, A. Bioavailability of Polyphenon E flavan-3-ols in humans with an ileostomy. J. Nutr. 2008, 138, 1535S-1542S

20. Mullen, W.; Borges, G.; Donovan, J.L.; Edwards, C.A.; Serafini, M.; Lean, M.E.J.; Crozier, A. Milk decreases urinary excretion but not plasma pharmacokinetics of cocoa flavan-3-ol metabolites in humans. Am. J. Clin. Nutr. 2009, 89, 1784-1791 
21. Manach, C.; Williamson, G.; Morand, C.; Scalbert, A.; Rémésy, C. Bioavailability and bioefficacy of polyphenols in humans. I. Review of 97 bioavailability studies. Am. J. Clin. Nutr. 2005, 81, 2230S-2242S.

22. Roowi, S.; Stalmach, A.; Mullen, W.; Lean, M.E.J.; Edwards, C.A.; Crozier A. Green tea flavan-3-ols: colonic degradation and urinary excretion of catabolites by humans. J. Agric. Food Chem. 2010, 58, 1296-1304.

23. Clifford, M.N.; Copeland, E.L.; Bloxsidge, J.P.; Mitchell, L.A. Hippuric acid as a major excretion product associated with black tea consumption. Xenobiotica 2000, 30, 317-326.

24. Self, H.L.; Brown, R.R.; Price, J.M. Quantitative studies on the metabolites of tryptophan in the urine of swine. J. Nutr. 1960, 70, 21-25.

25. Grumer, H.D. Formation of hippuric acid from phenylalanine labelled with carbon-14 in phenylketonuric subjects. Nature 1961, 189, 63-64.

26. Bridges, J.W.; French, M.R.; Smith, R.L.; William, R.T. The fate of benzoic acid in various species. Biochem. J. 1970, 118, 47-51.

27. Mulder, T.P.; Rietveld, A.G.; van Amelsvoort, J.M. Consumption of both black tea and green tea results in an increase in the excretion of hippuric acid into urine. Am. J. Clin. Nutr. 2005, 81, 256S-260S.

28. Li, C.; Lee, M.J.; Sheng, S.; Meng, X.; Prabhu, S.; Winnik, B.; Huang, B.; Chung, J.Y.; Yan, S.; Ho, C.T.; Yang, C.S. Structural identification of two metabolites of catechins and their kinetics in human urine and blood after tea ingestion. Chem. Res. Toxicol. 2000 3, 177-184.

29. Meng, X.; Sang, S.; Zhu, N.; Lu, H.; Sheng, S.; Lee, M.J.; Ho, C.T.; Yang, C.S. Identification and characterization of methylated and ring-fission metabolites of tea catechins formed in humans, mice, and rats. Chem. Res. Toxicol. 2002, 15, 1042-1050.

30. Sang, S.; Lee, M.J., Yang, I., Buckley, B.; Yang, C.S. Human urinary metabolite profile of tea polyphenols analyzed by liquid chromatography/electrospray ionization tandem mass spectrometry with data-dependent acquisition. Rapid Commun. Mass Spectrom. 2008, 22, 1567-1578.

31. Del Rio, D.; Calani, L.; Cordero, C.; Salvatore, S.; Pellegrini, N.; Brighenti, F. Bioavailability and catabolism of green tea flavan-3-ols in humans. Nutrition 2010, [Epub ahead of print].

32. Larrosa, M.; Luceri, C.; Vivoli, E.; Pagliuca, C.; Lodovici, M.; Moneti, G,;Dolara, P. Polyphenol metabolites from colonic microbiota exert anti-inflammatory activity on different inflammation models. Mol. Nutr. Food Res. 2009, 53, 1044-1054.

(C) 2010 by the authors; licensee MDPI, Basel, Switzerland. This article is an Open Access article distributed under the terms and conditions of the Creative Commons Attribution license (http://creativecommons.org/licenses/by/3.0/). 